\title{
What defines airflow obstruction in asthma?
}

\author{
I. Cerveri*, A.G. Corsico*, S. Accordini" , G. Cervio*, E. Ansaldo*, A. Grosso*, \\ R. Niniano*, E. Tsana Tegomo*, J.M. Antó ${ }^{\tau,+, \S, f}$, N. Künzli ${ }^{\top, \S, f, * *}$, C. Janson ${ }^{\# \#,}$ \\ J. Sunyer ${ }^{\uparrow,+}, \S, f$, C. Svanes ${ }^{\uparrow \uparrow}$, J. Heinrich ${ }^{++}$, J.P. Schouten ${ }^{\S \S}$, M. Wjst ${ }^{++}$, \\ E. Pozzi* and R. de Marco ${ }^{\#}$
}

ABSTRACT: Asthma guidelines from the Global Initiative for Asthma (GINA) and from the National Heart, Lung, and Blood Institute provide conflicting definitions of airflow obstruction, suggesting a fixed forced expiratory volume in $1 \mathrm{~s}$ (FEV 1 )/forced vital capacity (FVC) cut-off point and the lower limit of normality (LLN), respectively. The LLN was recommended by the recent American Thoracic Society/European Respiratory Society guidelines on lung function testing. The problem in using fixed cut-off points is that they are set regardless of age and sex in an attempt to simplify diagnosis at the expense of misclassification.

The sensitivity and specificity of fixed FEV $1 /$ FVC ratios of $0.70,0.75$ and 0.80 versus the LLN were evaluated in 815 subjects (aged 20-44 yrs) with a diagnosis of asthma within the framework of the European Community Respiratory Health Survey.

In males, the $\mathbf{0 . 7 0}$ ratio showed $\mathbf{7 6 . 5 \%}$ sensitivity and $\mathbf{1 0 0 . 0 \%}$ specificity, the 0.75 ratio $100.0 \%$ sensitivity and $\mathbf{9 2 . 4 \%}$ specificity, and the 0.80 ratio $100.0 \%$ sensitivity but $58.1 \%$ specificity. In females, the 0.70 ratio showed $\mathbf{5 7 . 3} \%$ sensitivity and $\mathbf{1 0 0 . 0 \%}$ specificity, the 0.75 ratio $91.5 \%$ sensitivity and $95.9 \%$ specificity, and the 0.80 ratio $100.0 \%$ sensitivity but $72.9 \%$ specificity.

The fixed cut-off points cause a lot of misidentification of airflow obstruction in young adults, with overestimation with the 0.80 ratio and underestimation with the 0.70 ratio. In conclusion, the GINA guidelines should change their criteria for defining airflow obstruction.

KEYWORDS: Airflow obstruction, asthma, diagnosis

$\mathbf{T}$ he latest Global Initiative for Asthma (GINA) executive report states that, although the diagnosis of asthma is usually based on the presence of characteristic symptoms, patients with asthma frequently show poor recognition of their symptoms and poor perception of symptom severity [1]. Thus it is stressed that, for patients aged $>5$ yrs, measurements of lung function to confirm airflow obstruction greatly enhance diagnostic confidence. Most of all, spirometry is key to monitoring lung function as an outcome of asthma. The importance of objective assessment of pulmonary function has also been stressed in the 2007 full guidelines for the diagnosis and management of asthma report of the National Heart, Lung, and Blood Institute (NHLBI) [2]. However, these two guidelines on asthma provide conflicting definitions of airflow obstruction. Whereas the GINA guidelines state that the forced expiratory volume in $1 \mathrm{~s}(\mathrm{FEV} 1) /$ forced vital capacity (FVC) ratio is normally $>0.75-0.80$ in adults and that lower values suggest airflow obstruction [3], the NHLBI states that airflow obstruction is indicated by a reduction in FEV1/FVC relative to reference or predicted values [2]. Moreover, in several studies, the 0.70 fixed cut-off suggested by guidelines from the Global Initiative for Chronic Obstructive Lung Disease [4] has also been applied to asthmatic subjects [5-8].

In the present study, data from the European Community Respiratory Health Survey (ECRHS) were used to investigate the sensitivity and specificity of various fixed FEV1/FVC cut-off points with respect to the lower limit of normal (LLN), i.e. the lowest 5 th percentile of the frequency distribution of measures in a healthy population, according to the recent American Thoracic Society (ATS)/ European Respiratory Society (ERS) guidelines on lung function testing [9].

\section{METHODS}

\section{Study design}

The design of ECRHS I and ECRHS II has been described in detail elsewhere [10, 11]. In ECRHS I, an international multicentric study on respiratory in young adults with physician-diagnosed asthma
AFFILIATIONS

*Division of Respiratory Diseases, IRCCS San Matteo Hospital Foundation, University of Pavia, Pavia,

\#Unit of Epidemiology and Medical Statistics, Dept of Medicine and Public Health, University of Verona, Verona, Italy.

- Centre for Research in

Environmental Epidemiology,

+Universitat Pompeu Fabra,

${ }^{\S}$ CIBER en Epidemiología y Salud

Pública

fInstitut Municipal d'Investigació

Mèdica,

**Institució Catalana de Recerca i Estudis Avançats, Barcelona, Spain.

\#\#Dept of Medical Sciences,

Respiratory Medicine and Allergology, University of Uppsala, Uppsala, Sweden.

" Dept of Thoracic Medicine,

Haukeland University Hospital,

Bergen, Norway.

${ }^{++}$Institute of Epidemiology, GSF

National Research Center for

Environment and Health, Neuherberg.

Germany.

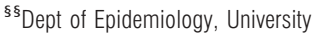
Medical Center Groningen, University of Groningen, Groningen, The Netherlands.

\section{CORRESPONDENCE}

A.G. Corsico

Clinica Malattie Apparato

Respiratorio

Fondazione IRCCS Policlinico San Matteo

via Taramelli 5

27100 Pavia

Italy

E-mail: angelo.corsico@unipv.it

Received:

Nov 142008

Accepted after revision:

Feb 202009

European Respiratory Journal

Print ISSN 0903-1936

Online ISSN 1399-3003 
diseases carried out during 1991-1993 on random samples of young adults aged 20-44 yrs, each participant was sent a brief screening questionnaire (stage 1), and, from those who responded, a random sample was selected to undergo a more detailed clinical and functional examination (stage 2). In addition, a symptomatic sample, formed by the subjects who had reported waking with shortness of breath, asthma attacks or use of asthma medication during stage 1, was studied.

In ECRHS II, a follow-up study of the participants in stage 2 of ECRHS I, performed during 1999-2002, the subjects were invited to undergo the same examination as in the first survey.

\section{Subjects and definitions}

A total of 13,113 subjects out of 16,638 participants in stage 2 of ECRHS I from 27 European centres, from the random and symptomatic samples, provided lung function measurements fulfilling the ATS criterion for reproducibility [12]. The present analysis was limited to the 815 subjects (355 males and 460 females) aged 20-44 yrs who also attended ECRHS II and who reported a diagnosis of asthma during their lifetime (positive answers to both of the questions "Have you ever had asthma?" and "Was this confirmed by a doctor?") during both of the surveys (ECRHS I and II), in order to minimise potential misclassification.

The subjects were grouped according to the presence of airflow obstruction during ECRHS I as defined by the LLN and fixed FEV1/FVC cut-off points. The LLN equations for FEV1/FVC were obtained from 1,227 males and 1,309 females [13] who participated in stage 2 of ECRHS I and who were defined as normal according to JOHANNESSEN et al. [14]. Predicted values and LLN equations for FEV1 and FVC were also calculated separately in males and females using the same methods as for FEV1/FVC ratio (table 1).

\begin{tabular}{|c|c|}
\hline TABLE 1 & $\begin{array}{l}\text { Predicted and lower limit of normal (LLN) lung } \\
\text { function equations for males and females from } \\
\text { the European Community Respiratory Health } \\
\text { Survey data }\end{array}$ \\
\hline \multicolumn{2}{|l|}{ Males } \\
\hline \multicolumn{2}{|c|}{ Predicted equation } \\
\hline FEV1 & $4.976 \mathrm{Ht}-0.020 \mathrm{~A}-3.695$ \\
\hline FVC & $6.957 \mathrm{Ht}-0.010 \mathrm{~A}-6.610$ \\
\hline $\mathrm{FEV}_{1} / \mathrm{FVC}$ & $89.602-0.185 A$ \\
\hline \multicolumn{2}{|c|}{ LLN equation } \\
\hline FEV1 & $4.976 \mathrm{Ht}-0.020 \mathrm{~A}-4.526$ \\
\hline FVC & $6.957 \mathrm{Ht}-0.010 \mathrm{~A}-7.602$ \\
\hline $\mathrm{FEV}_{1} / \mathrm{FVC}$ & $79.401-0.185 A$ \\
\hline \multicolumn{2}{|l|}{ Females } \\
\hline \multicolumn{2}{|c|}{ Predicted equation } \\
\hline FEV1 & $3.872 \mathrm{Ht}-0.019 \mathrm{~A}-2.412$ \\
\hline FVC & $5.251 \mathrm{Ht}-0.009 \mathrm{~A}-4.425$ \\
\hline $\mathrm{FEV}_{1} / \mathrm{FVC}$ & $94.644-0.287 A$ \\
\hline \multicolumn{2}{|c|}{ LLN equation } \\
\hline FEV 1 & $3.872 \mathrm{Ht}-0.019 \mathrm{~A}-3.021$ \\
\hline FVC & $5.251 \mathrm{Ht}-0.009 \mathrm{~A}-5.182$ \\
\hline $\mathrm{FEV}_{1} / \mathrm{FVC}$ & $85.101-0.287 A$ \\
\hline
\end{tabular}

FEV1: forced expiratory volume in $1 \mathrm{~s}$; FVC: forced vital capacity; Ht: height (in metres); A: age (in years).

\section{Statistical analysis}

The sensitivity and specificity of increasing fixed FEV1/FVC cut-off points were calculated using the LLN as the gold standard for defining airflow obstruction. For each fixed cutoff point, the $95 \%$ confidence interval of sensitivity and specificity was computed by logistic regression models with adjusted SEM for intragroup (i.e. ECRHS centre) correlation. The exact one-sided $97.5 \%$ confidence interval was calculated when the estimate of sensitivity or specificity was equal to $100.0 \%$. Youden's index was used to find the best fixed cut-off point [15]. Logistic regression models with adjusted SEM for intragroup correlation were also used to test the association between age and the percentages of false negatives (for the 0.70 cut-off point) and false positives (for the 0.80 cut-off point).

\section{RESULTS}

The demographic, clinical and functional characteristics during ECRHS I of the 815 subjects with physician-diagnosed asthma are reported in table 2 . Of these subjects, $236(29.0 \%)$ were classified as having airflow obstruction by the LLN, whereas $158(19.4 \%), 258(31.7 \%)$ and $428(52.5 \%)$ were classified as having airflow obstruction using the FEV1/FVC ratios of 0.70 , 0.75 and 0.80 , respectively. Using the LLN as the gold standard for defining airflow obstruction, the sensitivity and specificity of the 0.70 ratio were 76.5 and $100.0 \%$ for males, and 57.3 and $100.0 \%$ for females, respectively; the sensitivity and specificity of the 0.75 ratio were 100.0 and $92.4 \%$ for males, and 91.5 and $95.9 \%$ for females, respectively; and the sensitivity and

\begin{tabular}{|c|c|c|}
\hline TABLE 2 & \multicolumn{2}{|c|}{$\begin{array}{l}\text { Demographic, clinical and functional } \\
\text { characteristics during European Community } \\
\text { Respiratory Health Survey I of the } 815 \text { asthmatic } \\
\text { subjects considered in the analysis }\end{array}$} \\
\hline Females \% & & 56.4 \\
\hline \multicolumn{3}{|l|}{ Age \% } \\
\hline$<30 \mathrm{yrs}$ & & 38.8 \\
\hline $30-40$ yrs & & 37.7 \\
\hline$\geqslant 40 \mathrm{yrs}$ & & 23.5 \\
\hline \multicolumn{3}{|c|}{ Smoking status \% } \\
\hline Nonsmoker & & 50.8 \\
\hline Past smoke & & 20.5 \\
\hline Current sm & kers & 28.7 \\
\hline Smoking his & ory ${ }^{\#}$ pack-yrs & $8.6(3.5-16.0)$ \\
\hline FEV $1 \%$ pred & & $90.1 \pm 15.0$ \\
\hline FEV $1<$ LLN & & 23.2 \\
\hline FVC \% pred & & $97.2 \pm 12.8$ \\
\hline FVC $<$ LLN $\%$ & & 9.4 \\
\hline $\mathrm{FEV}_{1} / \mathrm{FVC}$ & & $78.1 \pm 9.8$ \\
\hline $\mathrm{FEV}_{\mathbf{1} / \mathrm{FVC}<1}<$ & LN \% & 29.0 \\
\hline High total Ig & & 46.8 \\
\hline IgE sensitisa & $\operatorname{ion}^{+} \%$ & 70.0 \\
\hline \multicolumn{3}{|c|}{$\begin{array}{l}\text { Data are presented as median (interquartile range) or mean } \pm \mathrm{SD} \text { unless otherwise } \\
\text { indicated. FEV }{ }_{1} \text { forced expiratory volume in } 1 \mathrm{~s} ; \% \text { pred: \% predicted; LLN: lower } \\
\text { limit of normal; FVC: forced vital capacity; Ig: immunoglobulin. } \\
\#: \text { among past and current smokers; } \%:>100 \mathrm{kU} \cdot \mathrm{L}^{-1} ;{ }^{+}: \text {at least one specific } \\
\text { IgE measurement of } \geqslant 0.35 \mathrm{kU} \cdot \mathrm{L}^{-1} \text { against five environmental allergens } \\
\text { (Dermatophagoides pteronyssinus, cat, timothy grass, Cladosporium herbarum } \\
\text { and a local allergen). }\end{array}$} \\
\hline
\end{tabular}




\begin{tabular}{|c|c|c|c|}
\hline \multirow{2}{*}{$\begin{array}{l}\text { TABLE } 3 \\
\text { Cut-off }\end{array}$} & \multicolumn{3}{|c|}{$\begin{array}{l}\text { Sensitivity, specificity and Youden's index of the } \\
\text { various forced expiratory volume in } 1 \text { s/forced } \\
\text { vital capacity fixed cut-off points }{ }^{\#} \text { by sex }\end{array}$} \\
\hline & Sensitivity & Specificity & $\begin{array}{l}\text { Youden's } \\
\text { index }\end{array}$ \\
\hline \multicolumn{4}{|l|}{ Males } \\
\hline 0.70 & 76.5 (69.9-82.0) & $100.0(98.4-100.0)^{\circ}$ & 0.76 \\
\hline 0.71 & $83.2(75.5-88.8)$ & $100.0(98.4-100.0)^{\bullet}$ & 0.83 \\
\hline 0.72 & 89.9 (82.1-94.6) & $99.2(94.0-99.9)$ & 0.89 \\
\hline 0.73 & $95.8(90.2-98.3)$ & 97.9 (94.2-99.2) & 0.94 \\
\hline 0.74 & 99.2 (94.0-99.9) & $95.3(90.9-97.7)$ & 0.94 \\
\hline 0.75 & $100.0(96.9-100.0)^{\circ}$ & $92.4(86.5-95.8)$ & 0.92 \\
\hline 0.76 & $100.0(96.9-100.0)^{\bullet}$ & $87.7(81.4-92.1)$ & 0.88 \\
\hline 0.77 & $100.0(96.9-100.0)^{\circ}$ & 80.9 (74.3-86.2) & 0.81 \\
\hline 0.78 & $100.0(96.9-100.0)^{\bullet}$ & 78.8 (72.8-83.8) & 0.79 \\
\hline 0.79 & $100.0(96.9-100.0)^{\circ}$ & $69.5(63.4-75.0)$ & 0.69 \\
\hline 0.80 & $100.0(96.9-100.0)^{\bullet}$ & $58.1(51.6-64.3)$ & 0.58 \\
\hline \multicolumn{4}{|l|}{ Females } \\
\hline 0.70 & $57.3(49.5-64.7)$ & $100.0(98.9-100.0)^{\circ}$ & 0.57 \\
\hline 0.71 & $68.4(58.7-76.7)$ & $100.0(98.9-100.0)^{\bullet}$ & 0.68 \\
\hline 0.72 & $72.6(63.0-80.5)$ & $100.0(98.9-100.0)^{\bullet}$ & 0.73 \\
\hline 0.73 & $84.6(77.7-89.7)$ & 99.4 (97.6-99.9) & 0.84 \\
\hline 0.74 & 88.0 (82.4-92.0) & $98.0(96.1-98.9)$ & 0.86 \\
\hline 0.75 & 91.5 (87.4-94.3) & 95.9 (93.0-97.7) & 0.87 \\
\hline 0.76 & 95.7 (91.3-98.0) & $92.1(88.8-94.5)$ & 0.88 \\
\hline 0.77 & 98.3 (94.0-99.5) & $88.3(84.0-91.6)$ & 0.87 \\
\hline 0.78 & $100.0(96.9-100.0)^{\bullet}$ & $84.3(79.4-88.1)$ & 0.84 \\
\hline 0.79 & $100.0(96.9-100.0)^{\natural}$ & $79.3(74.0-83.7)$ & 0.79 \\
\hline 0.80 & $100.0(96.9-100.0)^{\bullet}$ & $72.9(67.6-77.6)$ & 0.73 \\
\hline
\end{tabular}

Data are presented as \% (95\% confidence interval), unless otherwise stated. * using the lower limit of normal as the gold standard for defining airflow obstruction during European Community Respiratory Health Survey I; $"$ : exact one-sided $97.5 \%$ confidence interval.

specificity of the 0.80 ratio were 100.0 and $58.1 \%$ for males, and 100.0 and $72.9 \%$ for females, respectively (table 3; fig. 1). According to Youden's index, the best fixed cut-off point was 0.74 in males and 0.76 in females (table 3 ). With the 0.70 fixed cut-off point, the percentage of false negatives was significantly higher among younger males $(p=0.015)$ and females $(p=0.001)$ compared to older subjects (fig. 2), whereas the opposite was observed for the percentage of false positives when the 0.80 fixed cut-off point was used $(\mathrm{p}<0.001$ for both males and females) (fig. 3). With the 0.70 fixed cut-off point, the mean FEV1 was 95.0, 87.0 and $73.5 \%$ of the predicted value $(p<0.001)$ among subjects with normal lung function, those with misclassification of airflow obstruction and those with a concordant classification, respectively, whereas the mean FEV1 was $96.8,91.4$ and $78.0 \%$ pred $(p<0.001)$, respectively, when the 0.80 fixed cut-off point was used.

\section{DISCUSSION}

The present study shows that, among young adults with asthma, the use of FEV1/FVC fixed cut-off points of 0.70 and 0.80 causes a lot of misidentification of airflow obstruction, with overestimation of obstruction with the 0.80 ratio and underestimation with the 0.70 ratio. The extent of the
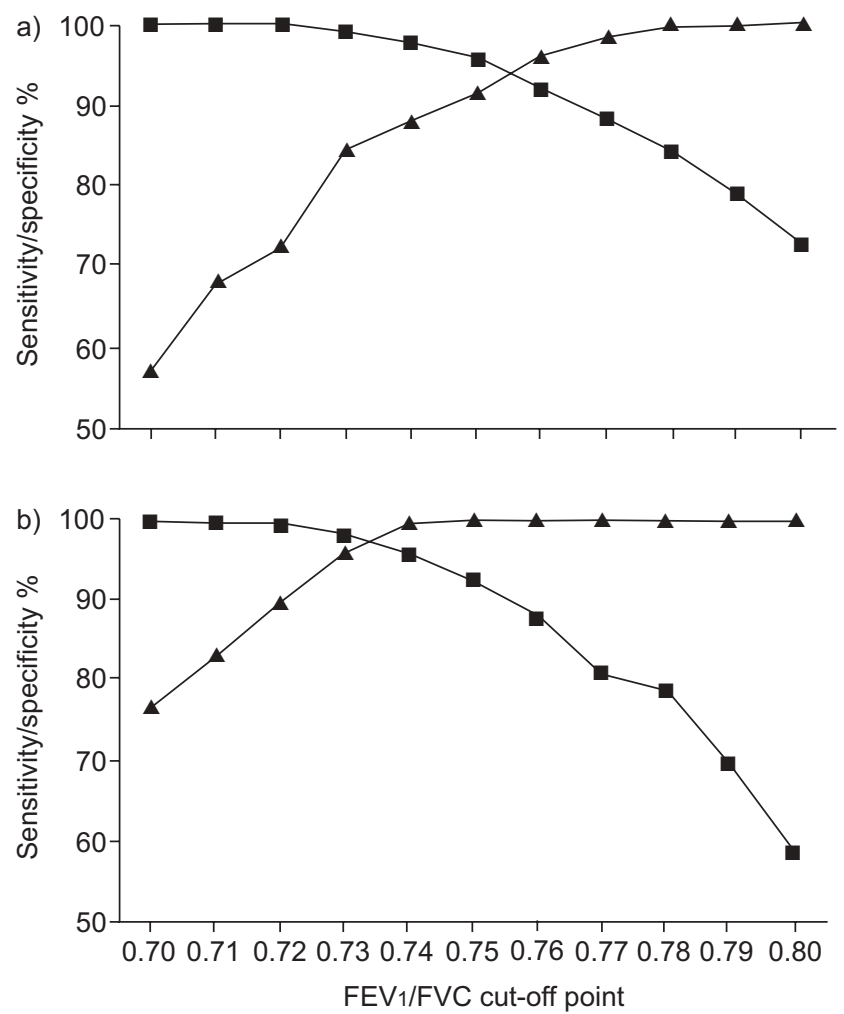

FIGURE 1. Sensitivity $(\boldsymbol{\Delta})$ and specificity $(\boldsymbol{\square})$ of increasing forced expiratory volume in $1 \mathrm{~s}(\mathrm{FEV} 1) /$ forced vital capacity (FVC) cut-off points using the lower limit of normal as the gold standard for defining airflow obstruction during European Community Respiratory Health Survey I in: a) females; and b) males.

misidentification was particularly high at the extremes of age, and differed between males and females.

Besides airflow obstruction, other important markers of asthma may help in better defining the individual asthma phenotype (IgE and airway inflammation) and its severity/ control (symptoms and medications). However, the relevance of pulmonary function, as both a diagnostic tool and an outcome of asthma, is recognised worldwide.

At present, there is lively debate concerning the definition of airflow obstruction specifically focused on COPD [16-22], and many authors have already demonstrated that the trade-off with simplicity and ease of remembrance of the 0.70 fixed cutoff point could come at the expense of misclassification [13, 2328]. The recommendation of different thresholds for the definition of airflow obstruction in COPD (0.70 ratio) and asthma (0.75-0.80 ratio) is even more difficult to justify and has resulted in ongoing confusion. The higher threshold for asthma than for COPD has probably been chosen because of the different distributions of age and the physiological decline in FEV1/FVC in the two diseases, even though asthma may also have a late onset. Most of all, the documentation of airflow obstruction is very important for the long-term management of the disease, as recently underlined in the third Expert Panel Report (EPR-3) [2]. The use of a fixed cut-off point in the monitoring of lung function of an asthmatic subject over their lifetime can cause underestimation of airflow obstruction when young and overestimation when old, providing a misleading 

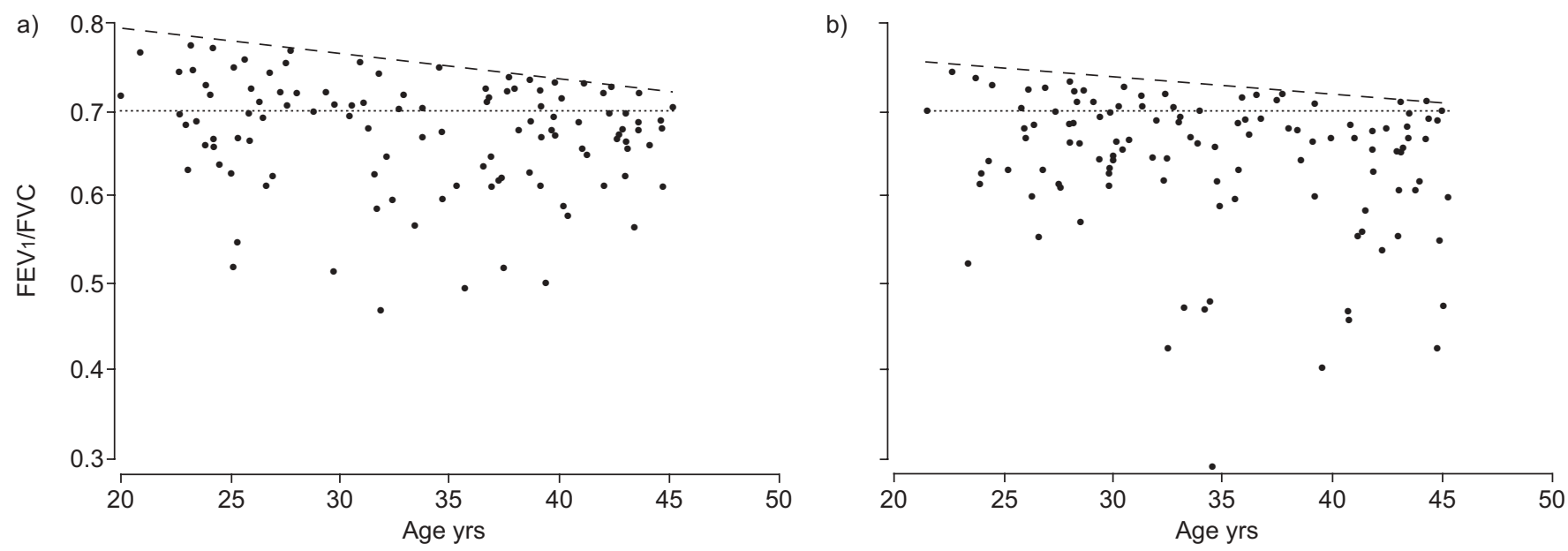

FIGURE 2. Forced expiratory volume in $1 \mathrm{~s}$ (FEV1)/forced vital capacity (FVC) ratio of the subjects classified as abnormal by the lower limit of normal (LLN) during European Community Respiratory Health Survey I in: a) females; and b) males. The LLN (---) and the 0.70 fixed cut-off point ( ( .........) are shown. Some of the subjects were above the stated age range as there was a lag between sampling frame selection and lung function assessment.

assessment of asthma control. Even the best cut-off points identified in the present study in the age range 20-44 yrs are expected to decrease in accuracy with increasing population age, as already documented for the 0.70 cut-off point in COPD [23-26].

According to the EPR-3 and American College of Physicians educational resources, the present results support the view that airflow obstruction is indicated by a reduction in FEV1/ FVC relative to reference or predicted values [2, 29]. This is physiologically appropriate since FEV1 declines more rapidly with age in normal subjects than does FVC; thus the FEV1/ FVC ratio decreases with age. Moreover, at variance with any fixed cut-off point, it takes into account the difference in lung function between males and females. However, even the most careful and rigorous scientific investigation could not yield an exact measurement. Rather, repeating an investigation would yield a scatter of measurements that are caused not only by error, but also by natural variability. In other words, measurements themselves, independent of any human or instrumental inaccuracies, exhibit scatter. Since all measurements contain inherent error, the exact or correct value of a measurement can never be identified. A natural consequence of this idea is that the approximation may occasionally be incorrect. Thus, a statistically derived level below which a value is considered abnormal was used since statistics help in the quantification of errors. As recommended by the ATS/ERS guidelines on lung function testing, an individual's lung function is, by convention, considered to be low if it is below the 5th percentile of the frequency distribution of values measured in healthy persons of equivalent sex and age [9]. Obviously, the choice of the 5th percentile is arbitrary, but it corresponds to the typical biostatistical level of the probability threshold that the result has occurred by statistical accident. It is important to realise

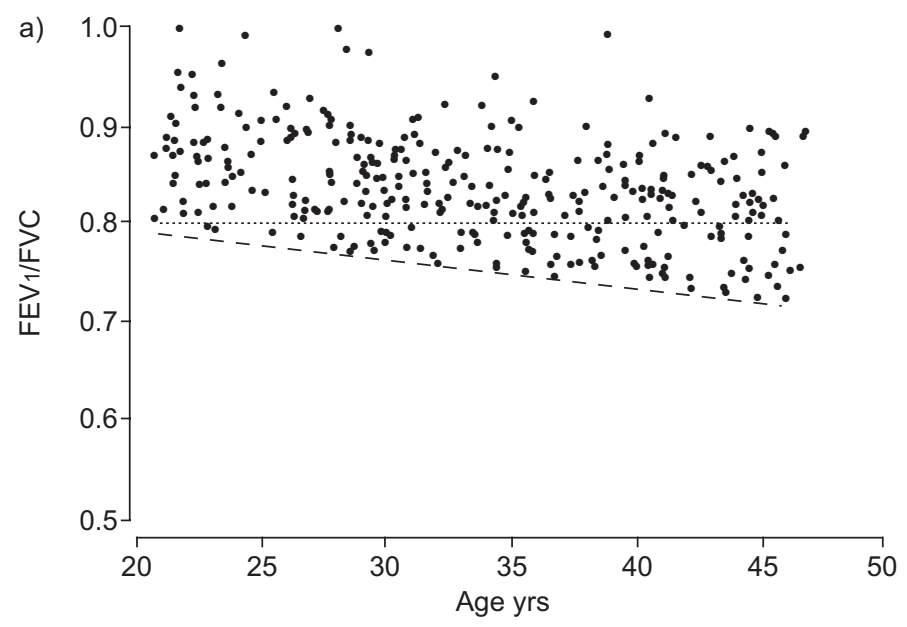

b)

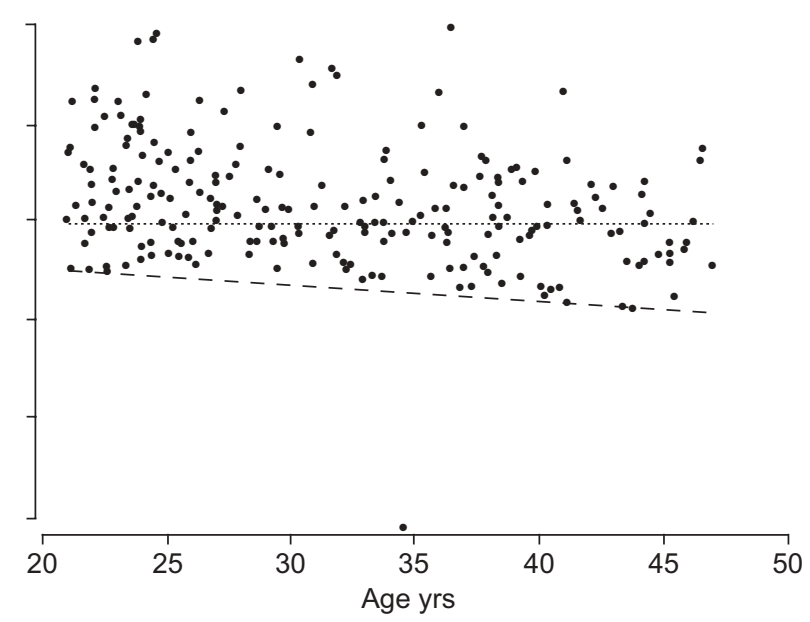

FIGURE 3. Forced expiratory volume in $1 \mathrm{~s}$ (FEV1)/forced vital capacity (FVC) ratio of the subjects classified as normal by the lower limit of normal (LLN) during European Community Respiratory Health Survey I in: a) females; and b) males. The LLN (---) and the 0.80 fixed cut-off point ( ..........) are shown. Some of the subjects were above the stated age range as there was a lag between sampling frame selection and lung function assessment. 
that there is always a finite chance that the result is a pure accident. In the present case it means that, by definition, $5 \%$ of the normal population (and only 5\%) exhibit values below than the LLN. The 5 th percentile of healthy subjects was applied to the asthmatic subjects even though patients with asthma do not show the same distribution of their FEV1/ FVC as healthy subjects because the aim was to identify airflow obstruction in a group of persons who differ from the norm in a way that is biologically disadvantageous.

The intrinsic limitation of using the LLN criterion is its dependency on the prediction equations and the reference population from which the prediction equations have been drawn. Ideally, prediction equations should be derived from measurements observed in a representative sample of healthy subjects from a general population, as in the present case, or, alternatively, in a large group of volunteers. Currently, the ATS/ERS committee does not recommend any specific set of equations for use in Europe, but suggests the need for a new Europe-wide study to derive updated reference equations [12]. Conversely, software and hardware have now changed the way in which laboratory testing is undertaken and there is no longer need for manual time-consuming calculation of predicted values, as even inexpensive spirometers can have built-in prediction equations and statistically derived LLNs.

The main strength of the present study is that it relies on a large international cohort of subjects from the general population. The ECRHS permitted derivation of the reference equations from measurements obtained in a representative sample of healthy subjects, using the same instruments and lung function protocol as in the followed-up cohort.

In conclusion, the present findings show the importance of using statistically valid spirometric criteria for the identification of airflow obstruction. Support is provided for the view that criteria for defining airflow obstruction in GINA guidelines should be changed.

\section{SUPPORT STATEMENT}

This study was supported, in part, by the Italian Medicines Agency, within the independent drug research programme (contract No. FARM5JYS5A). The co-ordination of the European Community Respiratory Health Survey (ECRHS) II was supported by the European Commission, as part of their Quality of Life Programme. The funding for the individual centres is listed on the ECRHS Website (www.ecrhs.org/ Funding\%20Sources.htm). All funds were used during the collection of data. The study design, analysis and interpretation of data, writing of the report and decision to submit the paper for publication were completely independent of these funds.

\section{STATEMENT OF INTEREST}

A statement of interest for J.M. Antó can be found at www.erj. ersjournals.com $/ \mathrm{misc} /$ statements.dtl

\section{ACKNOWLEDGEMENTS}

Coordinating centre (Dept of Public Health Sciences, King's College London, London, UK): project leader: P. Burney (Respiratory Epidemiology and Public Health Group, Imperial College, London, UK); statistician: S. Chinn (King's College London); principal investigator: D. Jarvis (Respiratory Epidemiology and Public Health Group, Imperial College); project coordinator: J. Knox (King's College London); principal investigator: C. Luczynska (King's College
London); assistant statistician: J. Potts (King's College London); and data manager: S. Arinze (King's College London).

European Community Respiratory Health Survey II steering committee: U. Ackermann-Liebrich (University of Basle, Basle, Switzerland); J.M. Antó (Institut Municipal d'Investigació Mèdica and Universitat Pompeu Fabra, Barcelona, Spain); P. Burney; I. Cerveri (University of Pavia, Pavia, Italy); S. Chinn; R. de Marco (University of Verona, Verona, Italy); T. Gislason (Iceland University Hospital, Reykjavik, Iceland); J. Heinrich (National Research Centre for Environment and Health Institute of Epidemiology, Munich, Germany); C. Janson (Uppsala University, Uppsala, Sweden); D. Jarvis; J. Knox; N. Künzli (Center for Research in Environmental Epidemiology at Institut Municipal d'Investigació Mèdica); B. Leynaert (Institut National de la Santé et de la Recherche Médicale, Paris, France); C. Luczynska; F. Neukirch (Institut National de la Santé et de la Recherche Médicale); J.P. Schouten (University Medical Center Groningen, University of Groningen, Groningen, the Netherlands); J. Sunyer (Institut Municipal d'Investigació Mèdica and Universitat Pompeu Fabra); C. Svanes (University of Bergen, Bergen, Norway); P. Vermeire (University of Antwerp, Antwerp, Belgium); and M. Wjst (National Research Centre for Environment and Health Institute of Epidemiology).

Principal investigators and senior scientific team. Belgium: South Antwerp and Antwerp city (P. Vermeire, J. Weyler, M. Van Sprundel and V. Nelen); Estonia: Tartu (R. Jogi and A. Soon); France: Paris (F. Neukirch, B. Leynaert, R. Liard and M. Zureik), and Grenoble (I. Pin and J. Ferran-Quentin); Germany: Erfurt (J. Heinrich, M. Wjst, C. Frye and I. Meyer); Iceland: Reykjavik (T. Gislason, E. Bjornsson, D. Gislason, T. Blondal and K.B. Jorundsdottir); Italy: Turin (M. Bugiani, P. Piccioni, E. Caria, A. Carosso, E. Migliore and G. Castiglioni), Verona (R. de Marco, G. Verlato, E. Zanolin, S. Accordini, A. Poli, V. Lo Cascio and M. Ferrari), and Pavia (A. Marinoni, S. Villani, M. Ponzio, F. Frigerio, M. Comelli, M. Grassi, I. Cerveri and A. Corsico); the Netherlands: Groningen and Geleen (J.P. Schouten and M. Kerkhof); Norway: Bergen (A. Gulsvik, E. Omenaas, C. Svanes and B. Laerum); Spain: Barcelona (J.M. Antó, J. Sunyer, M. Kogevinas, J.P. Zock, X. Basagana, A. Jaen and F. Burgos), Huelva (J. Maldonado, A. Pereira and J.L. Sanchez), Albacete (J. Martinez-Moratalla Rovira and E. Almar), Galdakao (N. Muniozguren and I. Urritia), and Oviedo (F. Payo); Sweden: Uppsala (C. Janson, G. Boman, D. Norback and M. Gunnbjornsdottir), Gothenburg (K. Toren, L. Lillienberg, A.C. Olin, B. Balder, A. PfeiferNilsson and R. Sundberg), and Umea (E. Norrman, M. Soderberg, K. Franklin, B. Lundback, B. Forsberg and L. Nystrom); Switzerland: Basle (N. Künzli, B. Dibbert, M. Hazenkamp, M. Brutsche, and U. Ackermann-Liebrich); and UK: Norwich (D. Jarvis and B. Harrison), and Ipswich (D. Jarvis, R. Hall and D. Seaton).

Centres taking part at their own expense. Australia: Melbourne (M. Abramson, R. Woods, E.H. Walters and F. Thien); France: Bordeaux (A. Taytard and C. Raherison), and Montpellier (J. Bousquet and P. Demoly); Germany: Hamburg (K. Richter); USA: Portland, OR (M. Osborne, S. Buist, W. Vollmer and L. Johnson).

\section{REFERENCES}

1 Bateman ED, Hurd SS, Barnes PJ, et al. Global strategy for asthma management and prevention: GINA executive summary. Eur Respir J 2008; 31: 143-178.

2 National Asthma Education and Prevention Program. Expert Panel Report 3 (EPR-3): guidelines for the diagnosis and management of asthma - summary report 2007. J Allergy Clin Immunol 2007; 120: Suppl. S94-S138.

3 Global Initiative for Asthma. Global Strategy for Asthma Management and Prevention. NIH publication No. 02-3659. Bethesda, National Institutes of Health, National Heart, Lung, and Blood Institute, 2006. 
4 www.goldcopd.com/Guidelineitem.asp? $11=2 \& 12=1 \&$ intId $=2003$ Global Initiative for Chronic Obstructive Lung Disease. Global Strategy for the Diagnosis, Management and Prevention of Chronic Obstructive Pulmonary Disease (updated 2008). Date last updated: January 2009. Date last accessed: 18 June 2009.

5 Lee JH, Haselkorn T, Borish L, et al. Risk factors associated with persistent airflow limitation in severe or difficult-to-treat asthma: insights from the TENOR study. Chest 2007; 132: 1882-1889.

6 Lehmann S, Bakke PS, Eide GE, et al. Clinical data discriminating between adults with positive and negative results on bronchodilator testing. Int J Tuberc Lung Dis 2008; 12: 205-213.

7 Lusuardi M, De Benedetto F, Paggiaro P, et al. A randomized controlled trial on office spirometry in asthma and COPD in standard general practice. Data from spirometry in asthma and COPD: a comparative evaluation Italian study. Chest 2006; 129: 844-852.

8 Murtagh E, Heaney L, Gingles J, et al. Prevalence of obstructive lung disease in a general population sample: the NICECOPD study. Eur J Epidemiol 2005; 20: 443-453.

9 Pellegrino R, Viegi G, Brusasco V, et al. Interpretative strategies for lung function tests. Eur Respir J 2005; 26: 948-968.

10 Burney PG, Luczynska C, Chinn S, et al. The European Community Respiratory Health Survey. Eur Respir J 1994; 7: 954-960.

11 European Community Respiratory Health Survey II Steering Committee. The European Community Respiratory Health Survey II. Eur Respir J 2002; 20: 1071-1079.

12 American Thoracic Society. Lung function testing: selection of reference values and interpretative strategies. Am Rev Respir Dis 1991; 144: 1202-1218.

13 Cerveri I, Corsico AG, Accordini S, et al. Underestimation of airflow obstruction among young adults using FEV1/FVC $<70 \%$ as a fixed cut-off: a longitudinal evaluation of clinical and functional outcomes. Thorax 2008; 63: 1040-1045.

14 Johannessen A, Omenaas ER, Eide GE, et al. Feasible and simple exclusion criteria for pulmonary reference populations. Thorax 2007; 62: 792-798.

15 Youden WJ. Index for rating diagnostic tests. Cancer 1950; 3: 32-35.
16 Fabbri LM, Boschetto P, Mapp CE. COPD guidelines: the important thing is not to stop questioning. Am J Respir Crit Care Med 2007; 176: 527-528.

17 Mannino DM. Defining chronic obstructive pulmonary disease . . and the elephant in the room. Eur Respir J 2007; 30: 189-190.

18 Pellegrino R, Brusasco V, Viegi G, et al. Definition of COPD: based on evidence or opinion? Eur Respir J 2008; 31: 681-682.

19 Miller MR. What defines abnormal lung function? Thorax 2007; 62 1107.

20 Townsend MC. Conflicting definitions of airways obstruction. Drawing the line between normal and abnormal. Chest 2007; 131: 335-336.

21 Enright PL. Are GOLDen slumbers drug induced? Am J Respir Crit Care Med 2008; 177: 1291.

22 Fabbri LM, Boschetto P, Mapp CE. Time to wake up! Am J Respir Crit Care Med 2008; 177: 1291-1292.

23 Hardie JA, Buist AS, Vollmer WM, et al. Risk of over-diagnosis of COPD in asymptomatic elderly never-smokers. Eur Respir J 2002; 20: 1117-1122.

24 Roberts SD, Farber MO, Knox KS, et al. FEV1/FVC ratio of $70 \%$ misclassifies patients with obstruction at the extremes of age. Chest 2006; 130: 200-206

25 Hansen JE, Sun XG, Wasserman K. Spirometric criteria for airway obstruction. Use percentage of FEV1/FVC ratio below the fifth percentile, not $<70 \%$. Chest 2007; 131: 349-355.

26 Medbø A, Melbye H. Lung function testing in the elderly - can we still use FEV1/FVC $<70 \%$ as a criterion of COPD? Respir Med 2007; 101: 1097-1105.

27 Swanney MP, Ruppel G, Enright PL, et al. Using the lower limit of normal for the FEV1/FVC ratio reduces the misclassification of airway obstruction. Thorax 2008; 63: 1046-1051.

28 Ko FW, Woo J, Tam W, et al. Prevalence and risk factors of airflow obstruction in an elderly Chinese population. Eur Respir J 2008; 32: 1472-1478.

29 Panettieri RA Jr. In the clinic. Asthma. Ann Intern Med 2007; 146: ITC6-1-ITC6-16. 